\title{
Dua Dimer Resveratrol dari Kulit Batang Shorea parvifolia (dipterocarpaceae)
}

\section{Kholifatu Rosyidah $^{1 *}$, Lia Dewi Juliawati²), Yana Maolana Syah²), Euis Holishotan Hakim²), Sjamsul Arifin Achmad $^{2)}$, dan Lukman Makmur'}

\author{
${ }^{1 *}$ Kimia, FMIPA, Universitas Lambung Mangkurat, Banjarbaru, Jl. A. Yani KM 35,8 Banjarbaru 70714 \\ 2)Kelompok Penelitian Kimia Organik Bahan Alam, Departemen Kimia, Institut Teknologi Bandung, \\ Jl. Ganesha 10 Bandung 40132
}

Diterima 30-05-2009 Disetujui 19-10-2009

\begin{abstract}
Two resveratrol dimers, (-)-ampelopsin F dan (-)-laevifonol were isolated from aceton extract of the stem bark of Shorea parvifolia. The structures of these compounds were determined based on their spectroscopic data including spectroscopy ultra violet (UV), infra red (IR), nuclear magnetic resonance $\left({ }^{1} \mathrm{H}-\mathrm{NMR},{ }^{13} \mathrm{C}-\mathrm{NMR}\right)$ and also were compared to the reported data.
\end{abstract}

keywords: (-)-ampelopsin F, (-)-laevifonol, Shorea parvifolia

\section{PENDAHULUAN}

Shorea merupakan genus terbesar dalam famili Dipterocarpaceae disamping Hopea (100 spesies) dan Dipterocarpus (75 spesies). Di Indonesia, Shorea atau "meranti" ditemukan sebanyak 150 spesies, di hutan Kalimantan terdapat 141 spesies, di pulau Sumatera terdapat 53 spesies, dan 4 spesies tersebar di wilayah Jawa sampai Papua Nugini (Newman 1999). Dari 150 spesies tersebut, hanya sedikit yang telah dikaji aspek kimianya. Shorea telah dilaporkan mengandung senyawa oligoresveratrol. Beberapa senyawa oligoresveratrol menunjukkan aktivitas biologi yang penting seperti anti tumor (Ohyama 1999), anti HIV (Dai 1998), anti inflamasi, anti jamur, dan anti bakteri (Kitanaka 1990). Shorea parvifolia adalah salah satu tumbuhan Dipterocarpaceae yang tersebar luas di Kalimantan, Sumatera, Malaya, dan Thailand. Beberapa senyawa oligoresveratrol yang telah dilaporkan dari Shorea parvifolia diantaranya (+)-(á)-viniferin, davidiol A (Rosyidah 2005), dan trans-miyabenol C (Rosyidah 2007) ketiga senyawa tersebut golongan trimer resveratrol. Pada kesempatan kali ini akan dilaporkan penemuan dua senyawa dimer resveratrol dari ekstrak aseton S. parvifolia.

\section{BAHAN DAN METODE}

Putaran optik ditentukan dengan menggunakan alat polarimeter Perkin-Elmer 341 dalam pelarut $\mathrm{MeOH}$. Titik leleh diukur dengan meggunakan alat penetapan titik leleh mikro Fisher John. Spektrum Ultra Violet (UV) ditentukan dengan spektrometer Cary Varian Conc. 100, sedangkan spektrum inframerah (IR) diukur dengan spektrometer FTIR Perkin Elmer Spectrum One. Spektrum NMR ditentukan dengan JEOL JNM A500 yang beroperasi pada $400 \mathrm{MHz}\left({ }^{1} \mathrm{H}\right)$ dan $100 \mathrm{MHz}\left({ }^{13} \mathrm{C}\right)$. Kromatografi Vakum Cair (KVC) dilakukan dengan menggunakan Silika gel G60. Kromatografi Radial menggunakan alat kromatotron dengan silika gel Merck $60 \mathrm{PF}_{254}$ dengan ketebalan plat 0,5 mm, 1,0 mm, dan 2,0 mm. Kromatografi Kolom Tekan (KKT) dengan silika gel Merck 60 (230-400 mesh) sedangkan Kromatografi Lapis Tipis (KLT) dilakukan menggunakan plat aluminium berlapis Silika gel Merck Kieselgel 60 GF $_{254}$ setebal $0,25 \mathrm{~mm}$. Semua pelarut yang digunakan berkualitas teknis yang didestilasi terlebih dahulu sebelum digunakan kecuali $\mathrm{CHCl}_{3}$ (p.a.). Larutan penyemprot (spraying agents) untuk penampak noda yang digunakan ialah serium sulfat $1,5 \%$ dalam asam sulfat $2 \mathrm{~N}$.

Bahan Tumbuhan. Bahan tumbuhan berupa kulit batang S. parvifolia dikumpulkan pada bulan Juli 2004 dari HPH PT Aya Yayang Indonesia (AYI) Camp 63, Tanjung, Tabalong, Kalimantan Selatan. Tumbuhan ini 
diidentifikasi di Herbarium Bogoriense, Lembaga IImu Pengetahuan Indonesia, Bogor dan spesimennya disimpan di herbarium tersebut.

Ekstraksi dan Isolasi. Sebanyak 2,97 kg serbuk kulit batang $S$. parvifolia dimaserasi dengan aseton. Ekstrak aseton diuapkan pelarutnya diperoleh $200 \mathrm{~g}$ ekstrak kering kemudian dipartisi dengan eter untuk mengendapkan tannin. Filtrat diuapkan hingga diperoleh ekstrak kering $(51,3 \mathrm{~g})$ yang relatif bebas tanin. Sebagian dari ekstrak tersebut $(20 \mathrm{~g})$ difraksinasi menggunakan KVC (Kromatografi Vakum Cair) (silika gel $150 \mathrm{~g}$ ) yang dielusi (masing-masing $150 \mathrm{ml}$ ) dengan campuran $n$-heksana-EtOAc yang meningkat kepolarannya (3:2 3x, 2:3 3x, 3:7 3x, 1:4 3x, 1:9 2x), EtOAc (2x), dan EtOAc-MeOH (4:1 2x). Proses yang sama dilakukan terhadap $20 \mathrm{~g}$ ekstrak sisanya. Fraksi yang sama digabung sehingga diperoleh enam fraksi utama A (6,4 g), B (2,0 g), C (3,7 g), D (3,3 g), E (1,8 $\mathrm{g})$, dan $\mathrm{F}(1,3 \mathrm{~g})$. Fraksi $D$ difraksinasi menggunakan kromatografi radial dengan eluen $\mathrm{CHCl}_{3}-\mathrm{MeOH} 5 \%$ sampai $20 \%$ diperoleh fraksi D1-D7. Selanjutnya, fraksi D2 $(270 \mathrm{mg})$ difraksinasi menggunakan kromatografi radial dengan eluen $\mathrm{MeOH}$ 5\% sampai $15 \%$ dalam $\mathrm{CHCl}_{3}$ diperoleh fraksi D21-D27. Pada fraksi D6 (637 $\mathrm{mg}$ ) difraksinasi dengan kromatografi radial dengan eluen $\mathrm{MeOH} 5 \%$ sampai $15 \%$ dalam $\mathrm{CHCl}_{3}$ diperoleh fraksi D61-D68. Fraksi gabungan D65 (30 mg), D25 (23 mg), dan D32 (21 mg) difraksinasi lagi menggunakan kromatografi radial dengan eluen $\mathrm{MeOH} 5 \%$ sampai $15 \%$ dalam $\mathrm{CHCl}_{3}$ diperoleh 2 fraksi gabungan D651 (8 $\mathrm{mg}$ ) dan D652 (40 mg). Fraksi D652 dimurnikan menggunakan kromatografi radial dengan eluen yang sama dan diperoleh senyawa 1 sebanyak $12 \mathrm{mg}$. Selanjutnya dilakukan pemisahan terhadap fraksi $E(2,0$ g) dengan KVC (silika gel $50 \mathrm{~g}$ ) yang dielusi (masingmasing $50 \mathrm{ml}$ ) dengan campuran $n$-heksana-EtOAc yang meningkat kepolarannya (3:7 10x, 1:4 4x, 1:9 $3 \mathrm{x}$ ), dan EtOAc (2x) memberikan delapan fraksi utama

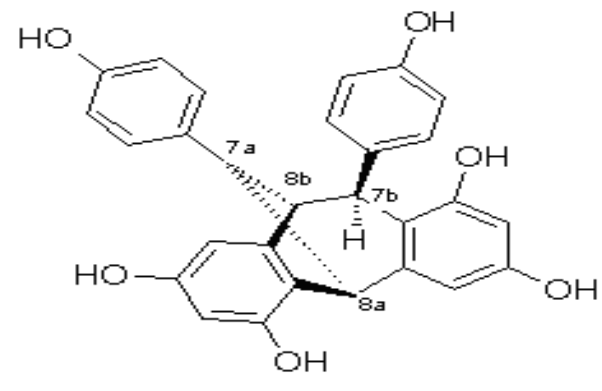

1
E1 (31 mg), E2 (48 mg), E3 (120 mg), E4 (300 mg), E5 (573 mg), E6 (314 mg), E7 (178 mg), dan E8 (454 mg). Terhadap E8 dilakukan pemisahan dengan $\mathrm{KR}$ yang dielusi dengan EtOAc $70 \%$ sampai $100 \%$ dalam $n$ heksana sehingga diperoleh E81 (97 mg), E82 (80 mg), dan E83 (130 mg). Pada fraksi E81 dilakukan pemurnian lebih lanjut dengan kromatografi radial yang dielusi dengan EtOAc $70 \%$ sampai $100 \%$ dalam $n$-heksana diperoleh senyawa 2 sebanyak $10 \mathrm{mg}$.

\section{HASIL DAN PEMBAHASAN}

Senyawa 1 berupa serbuk kuning, t.l. $165^{\circ} \mathrm{C}$ (terurai), [á] ${ }^{20}{ }_{\mathrm{D}}=-4^{0}($ c $0,1, \mathrm{MeOH}) . \mathrm{UV}(\mathrm{MeOH})$ senyawa 1 memperlihatkan serapan maksimum pada panjang gelombang $284 \mathrm{~nm}$ dan dengan penambahan $\mathrm{NaOH}$ mengalami pergeseran batokromik sebesar 14 $\mathrm{nm}$ menjadi $298 \mathrm{~nm}$ yang menunjukkan adanya kroofor fenol. Spektrum IR senyawa 1 menunjukkan serapanserapan khas untuk senyawa oligoresveratrol yaitu adanya gugus hidroksil (3338 $\left.\mathrm{cm}^{-1}\right), \mathrm{CH}$ aromatik (3028 $\left.\mathrm{cm}^{-1}\right), \mathrm{CH}$ alifatik $\left(2927 \mathrm{~cm}^{-1}\right), \mathrm{C}=\mathrm{C}$ aromatik (1611, $\left.1512,1456 \mathrm{~cm}^{-1}\right)$, serta gugus $p$-substitusifenil $835 \mathrm{~cm}^{-1}$ (Tukiran 2003).

Spektrum ${ }^{1} \mathrm{H}$-NMR menunjukkan adanya 2 pasang proton aromatik kopling orto pada $\ddot{\mathrm{a}}_{\mathrm{H}} 7,08(2 \mathrm{H}, d, J=$ $8,4 \mathrm{~Hz})$ dan $6,74(2 \mathrm{H}, d, J=8,4 \mathrm{~Hz}), 6,76(2 \mathrm{H}, d, J=$ $8,4 \mathrm{~Hz})$ dan $6,56(2 \mathrm{H}, d, J=8,4 \mathrm{~Hz})$ ppm yang menunjukkan adanya 2 gugus $p$-hidroksifenil. Spektrum ${ }^{1} \mathrm{H}-\mathrm{NMR}$ juga menunjukkan sinyal-sinyal untuk dua pasang proton aromatik kopling meta pada $\ddot{a}_{H} 6,06(1 \mathrm{H}$, $d, J=1,8 \mathrm{~Hz}, \mathrm{H}-12 \mathrm{a})$ dan $6,51(1 \mathrm{H}, d, J=1,8 \mathrm{~Hz}, \mathrm{H}-$ 14a), 6,15 (1H, $d, J=2,6 \mathrm{~Hz}, \mathrm{H}-12 \mathrm{~b})$ dan $6,44(1 \mathrm{H}, d$, $J=2,6 \mathrm{~Hz}, \mathrm{H}-14 \mathrm{~b}$ ) ppm yang menunjukkan adanya 2 gugus 1,2,3,5-tetrasubstifenil. Adanya 4 proton metin alifatik pada $\ddot{a}_{\mathrm{H}} 4,18(1 \mathrm{H}, d, J=1,8 \mathrm{~Hz}, \mathrm{H}-7 \mathrm{a}), 3,35$ $(1 \mathrm{H}$, brs, $\mathrm{H}-8 \mathrm{a}), 3,64(1 \mathrm{H}, \mathrm{s}, \mathrm{H}-7 \mathrm{~b})$ dan 4,12 $(1 \mathrm{H}, \mathrm{s}, \mathrm{H}-$ 8b) menunjukkan adanya sistem alifatik untuk kerangka cincin dibenzobisiklo[3,2,1]oktadiena. Spektrum ${ }^{13} \mathrm{C}$ -

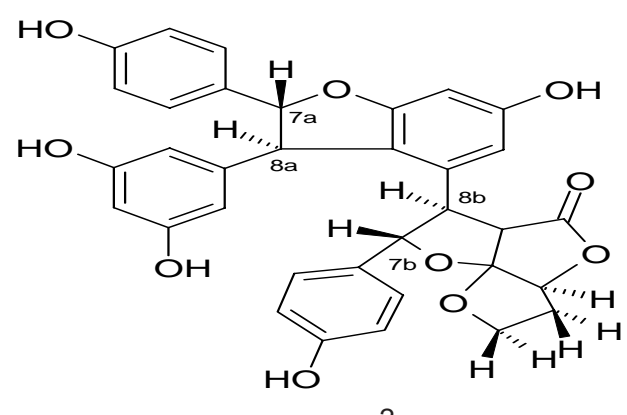


Tabel 1. Data ${ }^{1} \mathrm{H}$ dan ${ }^{13} \mathrm{C}-\mathrm{NMR}$ senyawa 1

\begin{tabular}{|c|c|c|c|c|}
\hline \multirow{2}{*}{ No. } & \multicolumn{2}{|c|}{$\delta_{\mathrm{H}}$ (multiplisitas, $J \mathrm{dlm} \mathrm{Hz}$ ) ppm } & \multicolumn{2}{|c|}{$\delta_{C} p p m$} \\
\hline & 1 & $1^{*}$ & 1 & $1^{*}$ \\
\hline $1 \mathrm{a}$ & & & 138,5 & 138,4 \\
\hline $2 a, 6 a$ & $7,08(d, 8,4)$ & $7,08(d, 8,5)$ & 130,0 & 129,8 \\
\hline $3 a, 5 a$ & $6,74(d, 8,4)$ & $6,74(d, 8,5)$ & 115,7 & 115,5 \\
\hline $4 a$ & & & 156,3 & 156,2 \\
\hline $7 a$ & $4,18(d, 1,8)$ & $4,18(d, 1,5)$ & 47,3 & 47,1 \\
\hline $8 a$ & 3,35 (brs) & $3,34(b r s)$ & 58,3 & 58,3 \\
\hline $9 a$ & & & 147,4 & 147,2 \\
\hline $10 a$ & & & 127,9 & 127,7 \\
\hline $11 a$ & & & 153,2 & 153,1 \\
\hline $12 a$ & $6,06(d, 1,8)$ & $6,07(d, 1,9)$ & 102,0 & 101,7 \\
\hline $13 a$ & & & 158,7 & 158,5 \\
\hline $14 a$ & $6,51(d, 1,8)$ & $6,51(d, 1,9)$ & 104,3 & 104,0 \\
\hline $1 b$ & & & 135,5 & 135,3 \\
\hline $2 b, 6 b$ & $6,76(d, 8,4)$ & $6,78(d, 8,5)$ & 129,3 & 129,3 \\
\hline $3 b, 5 b$ & $6,56(d, 8,4)$ & $6,58(d, 8,5)$ & 115,6 & 115,4 \\
\hline $4 b$ & & & 156,3 & 156,1 \\
\hline $7 b$ & $3,64(s)$ & 3,64 (brs) & 50,6 & 50,5 \\
\hline $8 b$ & $4,12(s)$ & $4,12(b r s)$ & 49,8 & 49,6 \\
\hline $9 b$ & & & 147,7 & 147,5 \\
\hline $10 \mathrm{~b}$ & & & 113,5 & 113,3 \\
\hline $11 b$ & & & 157,9 & 157,8 \\
\hline $12 b$ & $6,15(d, 2,6)$ & $6,17(d, 2,4)$ & 102,0 & 101,7 \\
\hline $13 b$ & & & 157,3 & 157,1 \\
\hline $14 b$ & $6,44(d, 2,6)$ & $6,44(d, 2,4)$ & 105,8 & 105,7 \\
\hline
\end{tabular}

1 (-)-ampelopsin $\mathrm{F}$ hasil isolasi

$1^{*}(-)$-ampelopsin F dari Caragana sinica (Luo, 2001)

1993). Penemuan senyawa 1 dalam $S$. parvifolia ini

NMR menunjukkan adanya 4 karbon alifatik pada $\ddot{a}_{H}$ 47,3 (C-7a), 58,3 (C-8a), 50,6 (C-7b), dan 49,8 (C-8b) yang tidak memiliki sistem cincin dihidroksi furan yang muncul pada geseran kimia $~ 90$ ppm serta 24 karbon aromatik yang menunjukkan bahwa senyawa 1 adalah dimer resveratrol.

Dalam genus Shorea, oligoresveratrol yang memiliki unit-unit seperti ini belum pernah ditemukan. Oligoresveratrol dengan unit-unit ini diantaranya (+)ampelopsin $\mathrm{F}$ dan (-)-ampelopsin F. Berdasarkan perbandingan data spektrum ${ }^{1} \mathrm{H}-\mathrm{NMR}$ dan ${ }^{13} \mathrm{C}-\mathrm{NMR}$ senyawa 1 dengan (-)-ampelopsin $\mathrm{F}$ yang diisolasi dari Caragana sinica (Luo 2001) pada Tabel 1 dapat disimpulkan bahwa senyawa 1 adalah (-) ampelopsin $\mathrm{F}$.

Senyawa 1 sebelumnya telah berhasil diisolasi dari Vatica umbonata (Atun 2004) sedangkan stereoisomernya yaitu (+)-ampelopsin $\mathrm{F}$ diisolasi dari Ampelopsin brevipecundulata varian hancei (Oshima sangat menarik karena dalam genus Shorea belum pernah ditemukan oligoresveratrol yang membentuk sistem cincin dibenzobisiklo $[3,2,1]$ oktadiena. Hal ini semakin memperkuat dugaan adanya kerangkakerangka struktur oligoresveratrol yang sangat beragam dalam genus Shorea.

Senyawa 2 diperoleh sebagai serbuk berwarna putih, t.l. $223^{\circ} \mathrm{C}$ (terurai), [á $]_{\mathrm{D}}^{20}=-139^{\circ}(\mathrm{c} 0,1, \mathrm{MeOH})$. Spektrum UV senyawa 2 memperlihatkan serapan maksimum pada panjang gelombang $284 \mathrm{~nm}$ yang merupakan ciri adanya kromofor benzena. Spektrum IR senyawa 2 memperlihatkan pita serapan untuk gugus $\mathrm{C}=\mathrm{O}$ dari ã-lakton $\left(1787 \mathrm{~cm}^{-1}\right)$ dan serapanserapan lain yang khas untuk suatu oligoresveratrol yaitu untuk gugus $\mathrm{OH}\left(3468 \mathrm{~cm}^{-1}\right), \mathrm{CH}$ alifatik (2920 $\left.\mathrm{cm}^{-1}\right), \mathrm{C}=\mathrm{C}$ aromatik $\left(1625,1515,1488 \mathrm{~cm}^{-1}\right)$ serta $p$ subtitusifenil $\left(837 \mathrm{~cm}^{-1}\right)$. Perbandingan spektrum IR senyawa 2 terhadap database IR memberikan korelasi $97 \%$ dengan senyawa (-)-laevifono ${ }^{9}$ dari S. pinanga Hasil 
KLT senyawa 2 dengan senyawa (-)-laevifonol menunjukkan harga $\mathrm{Rf}$ yang sama terhadap tiga sistem eluen yang berbeda.

Senyawa 2 merupakan satu-satunya dimer resveratrol yang berkondensasi dengan asam askorbat (Vitamin C). Sebelumnya senyawa ini telah dilaporkan berhasil diisolasi dari $S$. laevifolia), $S$. leprosula, $S$. balangerandan $S$. selanica, $S$. seminis dan S. Pinanga (Aminah 2003, Atun 2004 \& Tukiran 2003)

\section{KESIMPULAN}

Berdasarkan uraian di atas, dapat disimpulkan bahwa dua senyawa dimer resveratrol yaitu (-)ampelopsin F (1) dan (-)-laevifonol (2) telah diisolasi dari ekstrak aseton kulit batang $S$. Parvifolia. Struktur kedua senyawa tersebut ditetapkan berdasarkan berdasarkan data spektroskopi UV, IR, ${ }^{1} \mathrm{H}-\mathrm{NMR}$ dan ${ }^{13} \mathrm{C}-\mathrm{NMR}$ serta perbandingan dengan data sejenis dari senyawa yang sama yang telah dilaporkan.

\section{UCAPAN TERIMA KASIH}

Terima kasih disampaikan kepada Direktorat Jendral Pendidikan Tinggi atas bantuan beasiswa BPPs yang diberikan untuk melanjutkan studi program magister, kepada PT AYI Camp 63, Tanjung, Tabalong, Kalsel atas bantuan pengadaan sampel, kepada Herbarium Bogoriense, LIPI, Bogor yang telah membantu mengidentifikasi spesimen tumbuhan.

\section{DAFTAR PUSTAKA}

Aminah, N.S., Achmad, S.A., Hakim. E.H., Syah, Y.M., Makmur, L., Juliawaty L.D., Ghisalberti, E. \& Kitajima, M. 2003. Beberapa senyawa oligostibenoid dari kulit batang Shorea semiris (Dipterocarpaceae). Simposium Nasional Kimia Bahan Alam (SimNasKBA), Bandung.

Atun, S. 2004. Fitokimia beberapa spesies Dipterocarpaceae Indonesia dari genus Vatica, Anisoptera hopea dan Dipterocarpus. Disertasi Doktor. Bandung: Institut Teknologi Bandung.

Dai, J. R., Hallock, Y.F., Cardellina, J.H.H. \& Boyd, M.R. 1998. HIV inhibitory and cytotoxity oligostilbenes from the leaves of Hovea malibato. J. Nat. Prod. 64: 351-353.

Kitanaka, S., Ikezawa, T., Yasukawa, K., Yamanochi ,S., Takido, M., Sung, H-K. \& Kim, I-H. 1990. (+)- $\alpha$-viniferin, an anti-imflammatory compound from Caragana chamlagu Root. Chem. Pharm. Bull. 38: 432-435.

Luo, H-F., Zhang, L-P. \& Hu, C-Q. 2001. Five novel oligostilbenes from the roots of Caragana sinica. Tetrahedron. 57: 48494854.

Newman, M.F., Burgess, P.F. \& Whitmore, T.C. 1999 Pedoman identifikasi pohon-pohon Dipterocarpaceae Kalimantan:, PROSEA, Bogor, 216-217

Ohyama, M., Tanaka, T., Ito, T. linuma, M., Bastow, K.F. \& Lee, K.H. 1999. Antitumor agents 2001 cytotoxicity of naturally occuring resveratrol oligomers and their acetate derivatives. Bioorg.Med.Chem.Lett. 9: 3057-3060.

Oshima, Y., Ueno, Y., Hisamichi, H. \& Takeshita, M. 1993. Ampelopsin $\mathrm{F}$ and $\mathrm{G}$, novel bridged plant oligostilbenes from Ampelopsis brevipedunculata var. hancei roots (Vitaceae). Tetrahedron. 49: 5801-5804.

Rosyidah, K., Syah, Y.M., Achmad, S.A., Hakim, E.H., Makmur, L., Juliawati, L.D., Din, L.B., Latip, J. \& Said, IM. 2005. Dua senyawa oligomer resveratrol dari kulit batang Shorea parvifolia Dyer.(DIPTEROCARPACEAE). JSChem ITBUKM VI. Bali, 17-18 Mei 2005.

Rosyidah, K., Syah, Y.M., Achmad, S.A., Hakim, E.H., Makmur, L. \& Juliawati, L.D. 2007. Trans-Miyabenol C dari Kulit Batang Shorea parvifolia Dyer (DIPTEROCARPACEAE). Jurnal Obat Bahan Alam Universitas Kristen Widya Kartika 6: 1-5.

Tukiran. 2003. Senyawa Mikromolekul dari beberapa tumbuhan meranti (Shorea) Indonesia. Disertasi Doktor. Bandung: Institut Teknologi Bandung. 